\title{
Powerful qualities and pure powers
}

\author{
Henry Taylor $^{1}$ (D)
}

(C) The Author(s) 2017. This article is an open access publication

\begin{abstract}
Many think that properties are powers. However, whilst some claim that properties are pure powers, others claim that properties are powerful qualities. In this paper, I argue that the canonical formulation of the powerful qualities view (advocated by John Heil, C. B. Martin and others) is no different from the pure powers view. Contrary to appearances, the two positions accept the same view of properties. Thus, the debate between them rests on an illusion. I draw out some consequences of this surprising result for issues over property individuation. Along the way, I argue that all existing objections to the powerful qualities view fail.
\end{abstract}

Keywords Powerful qualities · Pure powers · Categoricalism · Individuation · Properties

\section{Powerful qualities and pure powers}

An increasingly popular view is that properties have a dispositional nature. Call this view dispositionalism. Opponents of dispositionalism think that the true nature of a property is not dispositional but 'categorical', 'quiddistic' or 'qualitative'. Call this categoricalism. Dispositionalism can come in a variety of flavours. One is the pure powers view, which claims that properties have a purely dispositional or powerful nature (Shoemaker 1980; Mumford 2004, 2006; Bird 2007a, b, 2016). ${ }^{1}$ Mumford describes a property as:

\footnotetext{
${ }^{1}$ Bird restricts his claim to fundamental properties.

Henry Taylor

jht30@cam.ac.uk

1 Department of Philosophy, University of Cambridge, Sidgwick Avenue, Cambridge CB3 9DA, UK
} 
nothing more than a set of connections to, and causal powers for, other properties (Mumford 2004, p. 185). ${ }^{2}$

Another version of dispositionalism claims that all properties are both dispositional and qualitative in nature. This is the powerful qualities view, primarily associated with C. B. Martin and John Heil.

The powerful qualities view has sometimes been interpreted as claiming that properties have different 'sides' or 'parts': a qualitative and a dispositional one (Armstrong 1997, p. 250). This is encouraged by some of Martin's early comments, where he describes each property as a 'two-sided coin' (1993, p. 184). However, even in early work Martin refers to the distinction between the qualitative and the dispositional as one of 'abstraction' (1993, p. 184) or 'conceptual artifice' (1996, p. 74), indicating that he doesn't think that the distinction is metaphysically substantive.

In later work, this issue is clarified. Martin and Heil remark that they are unhappy with the terminology of a two-sided coin (1998, p. 289). They also deny that properties are 'compounds' or 'a mixture' of dispositional and qualitative parts, or that the qualitative and dispositional are properties of properties (Martin and Heil 1999, pp. 46-47; Heil 2003, pp. 118-120; Martin 2008, p. 63). Rather, what they have in mind is an identity:

Our suggestion is that dispositionality and qualitativity are to be identified (Martin and Heil 1999, p. 47).

And:

the qualitative and dispositional are identical with one another and with the unitary intrinsic property itself (Martin 2008, p. 65).

The clearest statement of the view is as follows:

If $\mathrm{P}$ is an intrinsic property of a concrete object, $P$ is simultaneously dispositional and qualitative; $P$ 's dispositionality and qualitativity are not aspects or properties of $\mathrm{P}$; $\mathrm{P}$ 's dispositionality, $\mathrm{P}_{\mathrm{d}}$, is $\mathrm{P}$ 's qualitativity, $\mathrm{P}_{\mathrm{q}}$, and each of these is $\mathrm{P}: \mathrm{P}_{\mathrm{d}}=\mathrm{P}_{\mathrm{q}}=\mathrm{P}$ (Heil 2003, p. 111).

Note that the identity claim is threefold: the property, the dispositionality and the qualitativity of the property are all identical. I refer to this view as the identity thesis'. The identity thesis is the canonical version of the powerful qualities view: it is Martin and Heil's way of spelling the view out, and is also the version that has been adopted by those who have subsequently developed the powerful qualities view (Strawson 2008, p. 275; Jacobs 2011, pp. 89-90; Carruth 2016, pp. 27-28; Ingthorsson 2013, p. 57; Jaworski 2016, ch. 4; Engelhard 2010, pp. 51-52). This includes myself (Taylor 2013, pp. 94-95).

I will argue that the debate between the identity thesis and the pure powers view rests upon an illusion, because the pure powers view and identity thesis ultimately amount to the same view. Contrary to appearances, both views accept the same

\footnotetext{
${ }^{2}$ By 'connections' Mumford means the relations that properties bear to their stimuli and potential manifestations relations. Relations like these are accepted by all dispositionalists, though some prefer the label 'reciprocal partners' rather than 'stimuli'.
} 
ontology of properties. To be clear: this paper is not intended in the spirit of hostility. It is not meant to show that either view is false. The aim is rather to show that they are the same, and to draw out some of the consequences of this result.

Advocates of both the pure powers view and the identity thesis typically baulk at the suggestion that their views are the same. This is especially clear when we consider that one of the main motivations for the identity theory is its supposed superiority over the pure powers view (Martin 1997, 2008, pp. 61-63; Heil 2012, pp. 59-62; Jacobs 2011). Clearly, motivating the identity theory in this way assumes that the identity theory and the pure powers view are distinct. Likewise, Bird (a pure powers theorist) distances himself from Martin and Heil's view (2007a, pp. 514-515).

I proceed as follows: given that proponents of the views take them to be different, we can reasonably ask how they are supposedly different. Two possibilities suggest themselves. The first is that on both views properties are powers, but the identity theorist takes an extra step: she says that properties (and powers) are identical with qualities whilst pure powers theorists do not make this claim. I examine this suggestion in Sects. 2-3 (along the way I argue that all existing objections to the identity thesis fail). The second suggestion for distinguishing the two views is that the pure powers theorist also takes an extra step: she doesn't just claim that properties are powers, but that they are pure powers, whilst identity theorists do not make this claim. I examine this suggestion in Sect. 4. I argue that once we get clear on what these claims amount to, we see that they do not differentiate the two views, and that in fact the two views coincide (Sect. 5). I then consider some of the consequences of this for issues over property individuation (Sect. 6) and briefly suggest how progress in may be made (Sect. 7).

I remain neutral on debates about properties that are orthogonal to the issues of this paper, such as between Platonism and Aristotelianism (Tugby 2013; Armstrong 1997); whether dispositions have stimuli or reciprocal disposition partners (Bird 2007b; Martin 2008); whether properties are tropes or universals (Molnar 2003; Armstrong 1997) and whether dispositions are single-track or multi-track (Bird 2007b; Vetter 2013).

\section{What is a quality?}

Start with the suggestion that the identity thesis claims that properties are powers and qualities, whilst the pure powers view does not claim that properties are qualities. I shall argue that once we get clear on what a 'quality' is, we will see that pure powers views also accept that properties are qualities in all of the senses in which identity theorists accept that they are qualities. Terminological note: it is the job of this section to untangle several meanings of 'quality', so I will not define it in advance, nor will I make any assumptions about how it relates to the 'categorical'.

\subsection{Being and real features of objects}

Heil and Martin never give an explicit definition of 'quality', but they say much that is suggestive: 
qualities are categorical; qualities are here and now, actual, not merely potential, features of the objects of which they are qualities (Heil 2012, p. 59).

Heil also says that 'ways things are are qualities' (2010, p. 70). Notice that Heil allies the qualitative with the 'categorical'. Martin also does this, and equates being categorical with being 'really 'there' in the object' (1996, p. 74). In all of these senses of 'quality' given by Martin and Heil, pure powers theorists can agree that properties are qualities. To the pure powers theorist, the property of fragility is an actual property of the glass, which is really there in the glass, is 'here and now' and is part of the way the glass is. Pure powers theorists also claim (like Martin and Heil) that a property like fragility is not just a 'potential' feature of the glass, but an actual feature of it. Molnar says:

Having a power is... having an actual property...Powers are not merely the potentiality of some behaviour (2003, p. 99). ${ }^{3}$

So, in all of these senses of 'quality', both identity theorists and pure powers theorists accept that properties are qualities. Similar things apply to Galen Strawson's version of the identity theory, though he favours the term 'categorical' rather than 'qualitative'. He is clear about what he means by 'categorical':

[a]ll being is categorical being because that's what it is to be! That's what being is! (2008, p. 278).

Strawson equates 'categorical' simply with 'being'. Again, it is clear that in this sense of 'categorical', the pure powers theorist agrees that properties are categorical. After all, they accept properties into their ontology, so they must think that they have being!

\subsection{Illustration by example}

Can we use examples to understand what a quality is? Certainly, identity theorists use examples to illustrate their points. Heil describes shape and colour properties as 'paradigmatic qualities' (2012, p. 57. Cf Heil 2003, p. 113; Martin and Heil 1999, p. 46). Now, we are concerned with whether we can formulate a notion of 'quality' that can separate the two views. Examples cannot perform this task. Of course, all of the participants in this debate accept the existence of properties such as redness and sphericity, so merely pointing to these properties cannot tell us the difference between two supposedly distinct metaphysical accounts of those properties. So, for our particular purposes, examples cannot help.

\subsection{Qualia}

Adherents of the identity thesis often liken qualities to qualia, understood by reference to phenomenal consciousness. Such links have been drawn by Martin

\footnotetext{
${ }^{3}$ Molnar believes in pure powers and categorical properties in the traditional sense, here he is discussing powers.
} 
(1997, p. 193), Heil (2003, p. 76), Carruth (2016, p. 34) and Ingthorsson (2013, p. 66) but this issue has been most thoroughly examined by Jacobs (2011) so I concentrate on him. Jacobs takes the conscious experience of seeing red as an example, and says '[t]he qualitative nature of such properties, or 'qualia', forces itself upon us' (2011, p. 87). He says that 'pure powers cannot account for the phenomenological character of experience' (2011, p. 87) because 'phenomenal properties are richly qualitative in a way that pure powers are not' $(2011$, p. 91). He further claims that the identity theory can accommodate for phenomenal consciousness (2011, pp. 91ff.).

Jacobs draws a distinction between mental qualia and physical qualia, of which only the former are properties of mental events, whereas the latter are properties of physical objects. He claims that pure powers views cannot accept the existence of either mental or physical qualia (2011, p. 91), saying that 'if the pure powers view is correct, everything is zombie-like... empty of all qualitative nature' (2011, p. 87).

Let us start with 'physical qualia'. To Jacobs, these are not phenomenal properties, because he insists that his view is not panpsychism $(2011$, p. 91). This is important: for Jacobs, the notion of 'qualia' is not the same as the phenomenal, because he thinks that 'physical qualia' are not phenomenal. Rather, Jacobs says that physical qualia are 'thick quiddities' (2011, p. 90). The term 'quiddity' has been interpreted in various ways, and (as we shall see in Sect. 6.2) most of them take quiddities to be non-dispositional features of properties. Clearly, this cannot be what Jacobs means when he says that properties are thick quiddities because he is an identity theorist, so he cannot accept that properties are non-dispositional. Rather, what he means by a 'thick quiddity' is a property that has 'its own nature', he also says that: '[t]hick quiddities differ from each other, not merely numerically' that to encounter a thick quiddity is 'emphatically not to have encountered them all' (Jacobs 2011, pp. 90-91).

These are the features that Jacobs takes to be distinctive of thick quiddities. However, pure powers theorists can happily accept that properties have all of these features: they differ from each other, not merely numerically, they have their own nature, and to encounter one is not to encounter them all. So, given all of the things that Jacobs takes to be distinctive of 'thick quiddities', pure powers theorists claim that properties are thick quiddities. Again on this meaning of 'quality', pure powers theorists think that properties are qualities too.

Return to Jacobs' claim that pure powers theories cannot account for consciousness, but that the identity theorist can. Of course, the literature on consciousness is vast, and it would be silly to try to engage with it seriously here. Additionally, Jacobs does not give details of how the identity theory can account for consciousness, so it is difficult to assess his claims. However, for our purposes the following points are sufficient: recall that (for Jacobs) saying that a property is a 'quality' amounts to saying that it is a thick quiddity, in the sense explained above. But as we have seen, the pure powers view also claims that properties are thick quiddities in Jacobs' particular sense of 'thick quiddities'. So, if thick quiddities give the identity thesis the resources to account for conscious experiences, then the pure powers view has these resources as well, because both views accept that properties are thick quiddities. 
More generally, asking whether each view has the resources to account for phenomenal consciousness is unlikely to help in our current discussion, because we will not be able to assess how well each view can deal with consciousness until we have a clear idea of what each view is, and whether they are ultimately distinct. Only then would we be able to see what resources each view has, and what they have to say about consciousness. But trying to find the supposed difference between the two views is the whole problem we started with, and Jacobs' appeal to thick quiddities does not help. So it is unlikely that examining issues over consciousness will help in our current discussion. ${ }^{4}$

\subsection{Conceptual/epistemic distinctions}

Identity theorists often claim that the distinction between qualities and powers is only conceptual. Martin and Heil explain this in terms of the Lockean idea of 'partial consideration', a means by which we can attentively consider a property as qualitative or as dispositional. They use the analogy of the duck-rabbit to illustrate this (Heil 2003, pp. 119-120; Martin 2008, pp. 65-68; 1996, p. 132; Martin and Heil 1999 , p. 47). Strawson says something similar (though he phrases his claims in terms of the 'categorical' rather than the 'qualitative'):

[t]here's... a seemingly respectable conceptual (if ultimately metaphysically superficial) distinction between an object's categorical and dispositional properties (2008, p. 274).

Of course, saying that we can consider a property in a qualitative way already assumes a notion of the 'qualitative', which is something that we have encountered difficulty with. Still, the basic idea that Heil, Martin and Strawson are expressing is pretty clear: we can grasp, think about or refer to properties in two different ways, one of which associates with them certain dispositional descriptions, and another that does not.

Surely, this is a sensible claim. For example, we are able to grasp the property of 'sphericity' by way of a description that does not associate any dispositional features with it, for example: something is spherical iff. it is a 3-dimensional object that has all points on its surface equidistant from the centre (in Euclidean geometry). However, it is consistent with this that the actual property that this description picks out does have a dispositional nature and that we could grasp the very same property

\footnotetext{
${ }^{4}$ Sometimes, Jacobs characterizes the pure powers position as the view that properties are identical with the relations they enter into (2011, p. 84), based on some claims made by Bird and Mumford. However, it is doubtful that they would claim that powers are identical with their relations. After all, they claim that many powers are intrinsic properties, so it is hard to see how they could be relations (even if they claim that powerfulness can only be explicated relationally). In any case, the pure powers view is not even committed to the claim that powerfulness must be explicated relationally. Molnar, for example, thinks that some properties are pure powers, but denies that this should be cashed out entirely in terms of relations (2003, ch. 3). Heil (even whilst criticizing the pure powers view) is careful to distinguish it from a view on which all properties are purely relational (2003, pp. 79-84). More generally, notice that both views are in the same dialectical position here: both of them must accept the conditional that if powers are identical with relations, then properties themselves must be identical with relations. Though both views must accept this conditional, both views are free to deny the antecedent. Indeed, this is what they do.
} 
under some dispositional description, for example, by saying that it imbues objects with an ability to roll down an inclined plane, when combined with certain other properties such as solidity. ${ }^{5}$

As plausible as these ideas are, they cannot help us distinguish the identity view from the pure powers view, because the pure powers theorist can make the very same claims. The pure powers view is an ontological claim about the nature of properties. It is entirely consistent with this that we can grasp, describe or refer to properties in some way that does not associate them with dispositional descriptions.

Indeed, pure powers theorists explicitly agree that we can grasp, describe and refer to properties without using dispositional descriptions or predicates. Bird says:

We can certainly grasp shape concepts without associating them with dispositional characters (2007a, p. 514).

Bird even describes dispositional characterisations of shape as:

a rather convoluted way of characterizing something that can be so easily defined in non-dispositional terms (2009, p. 223).

He also claims that:

dispositional and non-dispositional expressions may co-refer (2012, p. 729).

It is not just Bird who makes these claims. In one of the papers that first launched the pure powers view, Shoemaker says:

Sometimes it belongs to the meaning, or sense, of a predicate that if it is true of a thing then under certain circumstances the thing will undergo certain changes or will produce changes in other things. This is true of what are standardly counted as dispositional predicates, for example, 'flexible', 'soluble'... it seems plain that predicates like 'square', and 'round' and 'made of copper' are not dispositional in this sense. There are causal powers associated with being made of copper... But presumably this association is not incorporated into the meaning of 'copper' (1980, p. 232).

More generally, the central question of this paper is an ontological one: what is the difference between an identity theorist's metaphysics of properties and a pure powers theorist's? The current suggestion doesn't speak to this concern because it is more of a claim about $u s$ and how we interact with properties conceptually, linguistically and epistemically, rather than a claim about properties themselves. None of this is intended as a criticism of Heil, Martin, Strawson, Bird or Shoemaker's suggestions, which are sensible and plausible. It is merely to point out that they cannot help us with the issue we are concerned with: distinguishing the two views ${ }^{6}$.

In this section, I have examined several interpretations of what a 'quality' is, and argued that on these interpretations of 'quality', both views claim that properties are

\footnotetext{
5 It is controversial whether shape properties have a dispositional nature but since all participants in this area must claim that they do, I set this issue aside.

6 Since pure powers theorists can accept that we have dispositional and non-dispositional ways of grasping properties, they can also lay claim to all of the theoretical advantages that result from invoking this conceptual distinction. I put more flesh on this conceptual distinction (and explain some theoretical benefits of adopting it) in my (Taylor 2017).
} 
qualities. ${ }^{7}$ In the next section, I argue that reflection on further notions of 'quality' sheds light on the most prominent objection to the identity theory.

\section{What qualities are not: the incoherence objection}

The most prominent objection to the identity theory is that it is incoherent, or commits some kind of category mistake. David Armstrong says:

If anything is a category mistake, it is a category mistake to identify a qualitya categorical property-and a power... They're just different, that's all. (2005, p. 315).

Similarly, Stephen Barker claims that the identity thesis 'looks incoherent' (2013, p. 649). To see why these thinkers take such a dim view of the identity theory, consider that in the above quotation, Armstrong allies a 'quality' with a 'categorical property'. He defines the categorical, in turn, as 'having a nature that is self contained, distinct from the powers' (1997, p. 69). Here Armstrong clearly defines the categorical as distinct from the powerful. Barker defines qualities as 'nonmodal' entities, whilst he understand dispositions as 'modal' (2013, p. 649).

If one defines a 'quality' in either of these ways, then of course it will be incoherent to identify qualities with dispositional/modal properties such as powers! However, as we have seen (Sect. 2), identity theorists do not ally the qualitative with the non-dispositional/non-modal: this is simply not what identity theorists mean by 'quality'. Rather, they understand it in terms of real, actual features of objects and so on. On these understandings of 'quality', it is not incoherent to identify a quality with a power. Similar things can be said about what the identity theorists mean by 'categorical': they mean properties that have being, and which are 'really there' in the object and so on. Once we get clear on what the identity theorists mean by 'quality' and 'categorical', the charge of incoherence fizzles out. ${ }^{8}$

\section{The purity of pure powers}

I have discussed what identity theorists mean by 'quality'. Now we can turn to what pure powers theorists mean by some of their claims. Specifically, they do not simply claim that properties are powers, but that they are pure powers (Bird 2007a). ${ }^{9}$

\footnotetext{
7 Another suggestion should be mentioned. Engelhard (2010) claims that a quality is a property considered as part of a particular state of affairs, whilst a disposition is a property considered as a universal, abstracted from the particular. However, this latches on to the trope/universal distinction rather than the disposition/quality distinction.

${ }^{8}$ Notice that this is why the identity thesis cannot collapse into traditional categoricalism: because traditional categoricalists claim that properties are categorical, and they define the 'categorical' as 'nondispositional'. Therefore (if we were to employ the understanding of the 'categorical' that traditional categoricalists use) identifying the categorical with the dispositional really would be incoherent.

9 Thanks to an anonymous referee for raising this.
} 
Similarly, pure powers theorists sometimes say that properties are 'nothing more' than powers (cf. Mumford 2004, p. 185) and sometimes that the powerfulness of a property exhausts its being (cf. Bird 2007b, p. 100). It may be thought that these comments separate the pure powers view from the identity thesis. After all, identity theorists do not claim that properties are pure powers. Heil explicitly says that properties are 'not purely dispositional' (2005, p. 346. Cf. Martin 2008, pp. 61-2).

Pure powers theorists do not explicitly spell out these 'purity', 'nothing more' and 'exhaustion' claims. This is unfortunate because (as we shall see) they are ambiguous in certain ways and they naturally invite extreme interpretation. However, I shall argue that once we get clear on what these claims mean, we will see that there is no disagreement to be found here between the pure powers view and the identity thesis.

\subsection{The extreme interpretation}

One interpretation of the claim that properties are 'pure' powers (or that they are 'nothing more' than powers, or 'exhaustively' powers) is that properties are powers, and also not qualities in the senses of 'quality' that the identity theorist has in mind. That is to say, they are powers, and not actual, real, 'thick' features of objects and so on. ${ }^{10}$ On this interpretation, the claim that properties are 'pure' powers amounts to the claim that powers do not fall into the category 'quality' (in the sense of 'quality' that the identity theorists mean). Of course, if this is what the pure powers theorists intend by these claims, then the view would clearly be distinct from the identity thesis.

However, this is altogether too extreme to be a plausible interpretation of what the pure powers theorists mean by the claim that properties are 'pure' powers, or 'exhaustively' powers, or 'nothing more' than powers. As I argued in Sect. 2, when we examine what pure powers theorists say, we see that they do think that properties are qualities in the senses that the identity theorists have in mind: they think that they are real, actual features of objects, and so on. Consider, for example, that when Bird makes the claim that the powerfulness of a property 'exhausts its being' (2007b, p. 100), this is within the context of an argument for the conclusion that powers are actual, real properties. So, when he makes this claim, he cannot be read as denying that properties are real, actual and so on.

A second reason to think that this extreme interpretation cannot be what pure powers theorists have in mind by these claims is charity. Any position that denied that properties are real, actual features of objects would very implausible. Even a small amount of charity leads us to conclude that this cannot be what the pure powers theorists mean. The final reason to think that this extreme interpretation is not what pure powers theorists have in mind comes when we consider some of the background committments of the pure powers theory. To a pure powers theorist, the claim that a property is nothing more than a power is not in tension with the claim that it has all of the features that identity theorists take to be marks of the

\footnotetext{
${ }^{10}$ By 'thick' features of objects, I am referring to Jacobs' claim that properties are 'thick quiddities' (Sect. 2.3).
} 
qualitative: that the property is real, actual and so on, because a core claim of the pure powers view is that a property's powerful nature is itself real, actual and so on.

A similarly extreme interpretation of the claim that properties are 'pure' powers, or 'nothing more' than powers, or 'exhaustively' powers is that all that we can say about properties is that they are powerful, or that the only way properties can be accurately described is in powerful/dispositional terms. ${ }^{11}$ However, for similar reasons, this interpretation is too extreme. As we have seen (Sect. 2.4), pure powers theorists explicitly accept that properties can be accurately described in ways that do not associate them with dispositional/powerful characters, and that we are not limited to describing them only in dispositional terms.

Once again, another reason not to attribute this interpretation of the 'purity' claim to the pure powers theorists is charity. It is clearly true that we are not limited to thinking about and describing properties in a dispositional manner. Indeed, as we saw with the sphericity example in Sect. 2.4, clearly we can accurately describe properties in a way that doesn't associate them with any dispositional characters. No view should deny this obvious truism. For this reason, if we interpreted the claim that properties are pure powers as denying this truism, then the pure powers view would not just be false, but clearly and obviously false. Charity dictates that we not ascribe such a view to them. More generally, a point made above is again relevant here. The pure powers view is a metaphysical one about the nature of properties, rather than a view about us and how we interact with them. Given this, it would be out of place to interpret their 'purity' claims as claims about how we can describe or think about properties.

I have argued that these extreme interpretations of the claims that properties are 'pure' powers, or 'exhaustively' powers, or 'nothing more than' powers do not accurately reflect what the pure powers theorists have in mind. Now, return to the fact that Heil (an identity theorist) claims that properties are not 'purely dispositional'. He fleshes out this claim by saying that properties are powers and qualities, and gives examples of shape and size (2005, p. 346). This indicates that when he says properties are not 'purely dispositional', what he is rejecting is an extreme version of the 'purity' claim: that properties are powers and also not qualities in the senses of 'quality' that he (as an identity theorist) has in mind. On this interpretation of the purity claim, Heil is absolutely right to reject it, but (as we have seen in this section) this is not what pure powers theorists have in mind when they make the purity claim. ${ }^{12}$ So, rejecting the purity claim on this interpretation does not mark a difference between the pure powers view and the identity theory.

\subsection{The denial of Armstrongian categorical properties}

Though pure powers theorists do not mean to deny that properties are 'qualities' in the senses in which the identity theorists claim that properties are qualities, it is certainly true that pure powers theorists deny that properties are 'categorical'

\footnotetext{
11 Thanks to an anonymous referee for suggesting this.

12 Of course, Heil may also be rejecting the claim that we cannot accurately describe properties using non-dispositional concepts. As already argued, the pure powers theorists also reject this.
} 
(Mumford 2006; Bird 2007b, ch. 4). This forms the basis of our second interpretation of the claim that properties are 'pure' powers: that properties are powers and not 'categorical' properties.

When pure powers theorists deny that properties are categorical, they mean the Armstrongian sense of 'categorical' that we encountered in Sect. 3: properties that are defined in opposition to dispositions/powers. To see that this is what pure powers theorists mean by 'categorical', consider that Mumford uses the terms 'categorical' and 'non-dispositional' interchangeably (e.g. 2006, p. 477). Similarly, Bird says:

What we mean by 'categorical' must be understood in negative terms... To say that a property is categorical is to deny that it is necessarily dispositional (2007b, pp. 66-67).

So, when pure powers theorists deny the existence of categorical properties, they are denying Armstrongian categorical properties. As I argued in Sect. 3, identity theorists must also reject the claim that properties are 'categorical' in this sense, on pain of incoherence. Indeed, we find that identity theorists explicitly do reject the existence of non-dispositional properties (Martin 2008, p. 66; Heil 2003, ch. 9). In the quotation given above, Bird defines 'categorical' properties as those properties that are not necessarily dispositional, and rejects their existence. Of course, the identity theorist must agree with Bird that categorical properties in this sense do not exist, because the identity theorist claims that properties are identical with dispositions. Indeed, Heil argues at length against the existence of properties that are not necessarily dispositional (2012, pp. 75-78).

The terms 'categorical' and 'quality' are both ambiguous, and are often used interchangeably. There is also a sense of 'quality' (employed by opponents of the identity thesis such as Armstrong and Barker, but not employed by the identity theorists), which allies the qualitative with the non-dispositional. Furthermore, identity theorists sometimes use the term 'categorical' to describe their own view of properties (Strawson 2008). ${ }^{13}$ As a result, it can easily appear as though pure powers theorists are disagreeing with the identity theorists by denying that properties are categorical. However, once we get clear on what the pure powers theorists mean when they deny the existence of 'categorical' properties, we see that the identity theorists deny the existence of such properties as well.

\subsection{Complete powerfulness}

A third interpretation of the claims that properties are 'pure' powers, or 'nothing more' than powers, or 'exhaustively' powers is that the whole nature of a property is powerful: all of it is powerful and there is no part of a property's nature that is nonpowerful. To my ear, this is the most natural way to interpret these claims. ${ }^{14}$

\footnotetext{
13 As we saw in Sect. 2.1, what Strawson means by 'categorical' is simply properties that have being.

14 Of course, this interpretation should not be taken to also imply that properties are not qualities in the senses that the identity theorists intend, as then we would have arrived back at interpretation 1 .
} 
It is clear that identity theorists are committed to this claim as well: identity theorists must also say that the whole nature of a property is powerful, and that there is no part of a property's nature that is non-powerful, because identity theorists claim that properties are identical with powers. On this view a property is a power. Once one accepts this identity claim, one clearly cannot deny that the whole nature of a property is powerful, and one cannot claim that there is some part to a property's nature that is non-powerful. ${ }^{15}$

Of course, on the identity thesis, it is just as correct to say that a property is a quality. This is true, but it is completely consistent with the claim that the whole nature of a property is powerful, and that there is no aspect of the property's nature that is non-powerful. After all, on this view the qualitativity of the property is itself identical with a power: it just is a power. So the nature of a quality is itself entirely powerful, and there is no aspect to a quality's being that is non-powerful. So, to say that a property is a quality is not in any way to disagree with this interpretation of the 'purity' claim.

\subsection{Summary}

We have examined three interpretations of the claim that properties are 'pure' powers, or that they are 'exhaustively' powers, or 'nothing more' than powers:

i) Properties are powers, and they are not qualities in the senses of 'quality' that the identity theorist has in mind, and/or they cannot be accurately described in ways that do not associate them with their dispositional characters.

ii) Properties are powers, and they are not 'categorical' or 'qualitative' in the Armstrongian sense of these terms.

iii) The whole being of a property is powerful, and there is no part of a property that is non-dispositional/non-powerful.

I have argued that the pure powers theorists and the identity theorists will both deny (i), both will accept (ii), and both will accept (iii). These claims are easy to interpret in very extreme ways, which exacerbates confusion in the debate. Nonetheless, with disambiguation, we see that both sides agree here.

\section{Positive and negative qualities}

We have a cluster of different senses of 'quality', which are importantly distinct but often blurred together. Some ally the qualitative with the non-dispositional, the nonmodal, the not-necessarily-dispositional or something of the sort. Call these the negative senses. But there are also other important senses on which a property can be 'qualitative' such as being actual, real, 'really there', accounting for colours and

\footnotetext{
15 As we saw in Sect. 1, identity theorists do explicitly reject the claim that properties have nondispositional parts, because they reject the 'compound' view.
} 
shapes, or being a property that can be grasped using non-dispositional predicates or concepts. Call these the positive senses of 'quality'. Ultimately, the pure powers theorists and the identity theorists come from the same place: both are keen to emphasise that properties are powers, and deny that properties are qualities in the negative senses. They also believe that properties have all of the features that are captured by the positive senses of 'quality'. Everyone here agrees that properties are powers, and that they are qualities in the positive senses, but not in the negative senses.

The same goes for the claim that properties are 'pure' powers, or 'exhaustively' powers, or 'nothing more' than powers. Everyone rejects the implausibly extreme versions of this claim, and accepts more moderate versions of them. These are the fundamental points that identity theorists and pure powers theorists have both been driving at. Once we realise this, we see that the two views share the same commitments concerning the ontology of properties: both accept that properties are powers, both accept that they are 'qualities' in the same ways, and both accept the same interpretations of the 'purity' claims. The two views have coincided.

\section{Property individuation}

In this section, I outline some of the consequences of my argument for our assessment of the two views. In Sect. 3, I discussed the most prominent objection to the identity theory. I now consider the most prominent objection to the pure powers view: the regress problem concerning property individuation. This objection has been pressed by identity theorists against the pure powers view (Heil 2003, pp. 107-108; 2012, p. 76; 2013, p. 31). However, if what I have argued is correct and the two views coincide, then we would expect the identity theory to face the problem just as much as the pure powers theory. I shall now argue that this is indeed the case.

\subsection{The individuation problem}

The individuation problem comes in various forms, but I follow the canonical formulation from Lowe (2006, p. 138). It can be summarised as follows: the pure powers theorist is committed to the claim that the dispositionality of a property is sufficient to fix its identity or to individuate it. In other words, the pure powers view is committed to the claim that the dispositionality of a property is sufficient to make it the very property that it is. However (according to the proponent of the individuation argument) this commitment is a problem, because the dispositionality of a property cannot fix its identity. This (argues the proponent of the individuation argument) is because the dispositionality of a property is itself fixed (at least in part) by its stimuli and manifestations. ${ }^{16}$ However (to the pure powers theorist) stimuli and manifestations are themselves just more powers, which must rely on their

\footnotetext{
16 As noted in Sect. 1, some use the term 'reciprocal disposition partners' rather than 'stimuli', but this will not matter for present purposes.
} 
stimuli/manifestation relations to fix their identities... and so on. The proponent of the individuation argument claims that this leads to a vicious circle or vicious infinite regress, with the result that 'no property can get its identity fixed' (Lowe 2006, p. 138).

Pure powers theorists have responded to the problem (Bird 2007a). However, my concern is not with whether these responses work, but with how the individuation problem applies to the identity thesis. Notice that the problem arises for the pure powers view because it is committed to the claim that the dispositionality of a property is sufficient to fix its identity. This commitment is what generates the problem because (claims the proponent of the individuation argument) dispositionality cannot be sufficient to do this. However, notice that the identity view is also committed to the problematic claim that a property's dispositionality is sufficient to fix its identity. The identity theory cannot claim that the property's dispositionality is insufficient to make it the thing that it is, because (on this view) the property is itself identical with a dispositionality. Given this identity claim, once we have the dispositionality in place, we have the whole property: there is no aspect to the property's nature that remains unfixed by its dispositionality because there is an identity here. This is the same problematic commitment that generates the problem of individuation for the pure powers view. Since the identity theory also has this commitment, the same argument can be run for the identity view: the dispositionality must itself be fixed by its stimuli and manifestations, which are themselves more powers... and so on.

To reemphasise: I am not claiming that the individuation argument is fatal to these views, I am only claiming that it is as much of a problem for the identity theory as the pure powers theory. In defence of the identity theory, it may be pointed out that (on the identity theory) one may as well say that properties' identities are fixed by their qualitative character. Indeed, identity theorists do invoke qualities to answer the problem of individuation, saying that qualities 'play a central role in the individuation of powers' (Heil 2010, p. 64).

Though it is correct to say that (on the identity view) a property's qualitative character fixes its identity, this will not allow the identity thesis to claim an advantage over the pure powers view, for two reasons. Firstly (as I have argued) there is no notion of 'quality' on which the identity theorist accepts that properties are qualities, but pure powers theorists reject them. So, in the senses in which the identity theorist can appeal to 'qualities', the pure powers theorist can do so also: the identity thesis has no advantage over the pure powers view. We can see this issue playing out with relation to a concrete example. To illustrate the role that qualities play in individuating powers, Heil uses an imaginary example of a blue sphere that has the power to attract yellow things, saying:

Blue spheres are 'yellow attractors'. We have a qualitative mode of individuation for a power (2012, p. 74).

The pure powers theorist can give precisely the same answer: she can also accept that certain powers are to be individuated by reference to colours such as blueness or yellowness (recall from Sect. 2.2 that the pure powers theorist can also appeal to colours). So, the pure powers theorist has access to this explanation just as much as the identity theorist does. 
The second reason to think that appeal to qualities cannot help the identity theorist runs very deep. Whatever else is true of qualities, on the identity theory, qualities ultimately are dispositionalities (because they are identical with them). But the whole problem of individuation arose precisely because (according to the individuation problem) dispositionalities are simply ill equipped to fix the identity of properties. So, saying that qualities fix the identity of a property cannot help the identity theorist. To put this problem another way, consider that pure powers theorists can appeal to further properties to explain how a property gets its identity fixed, but this does not help precisely these further properties are just more dispositionalities, and the whole problem is that dispositionalities cannot fix the identities of properties (at least, according to the individuation argument). Correlatively, if one is an identity theorist, appealing to qualities can be met with an analogous response: qualities are just dispositionalities on this view, and the whole problem is that dispositionalities cannot fix the identity of a property.

Of course, the identity theorist could deny some premise in the individuation argument. She could claim that we do not need to appeal to stimuli or manifestations to explain how a property gets its identity fixed, or she could accept this claim and argue that it is not a problem. Fair enough, but clearly these options are also available to the pure powers view. The identity theory confers no advantage.

\subsection{Quiddities}

There is a literature on 'quiddities', much of which is concerned precisely with explaining how properties' identities are fixed. Can the identity theorist draw upon this to flesh out a notion of 'quality' that can solve the problem of individuation? No, because (as I shall now argue) any notion of a 'quiddity' that can help solve the problem of individuation is inconsistent with the identity theory (I consider three):

i) Lewisian quiddities are non-dispositional features of a property that primitively fix the identity of properties, and can retain a change in a property's dispositionalities (Lewis 2001).

Clearly, this cannot be true of qualities on the identity view, because on this view qualities are identical with dispositionalities, and so cannot be identical with nondispositional features, and cannot survive a change in dispositional features.

ii) Dustin Locke (2008) identifies a version of quidditism on which the identity of properties is fixed by a bare numerical identity, not by its dispositionality.

This cannot be what the identity theorist means by a 'quality' because claiming that a quality is a bare numerical identity runs counter to identifying it with a dispositionality, which is not just a bare numerical identity.

iii) Deborah Smith isolates another notion of 'quiddity' on which a quiddity is an intrinsic nature which fixes the identity of the property, and is 'distinct from and in no way exhausted by' the property's dispositional nature (2016, p. 251). 
The identity theorists cannot accept that a quality is a quiddity in Smith's sense, because they cannot accept that a quality is distinct from the property's dispositional nature.

Could the identity theorist modify one of these notions of a 'quiddity' so that we can identify a quiddity with the dispositional nature of a property? Not if they want to use quiddities to solve the problem of individuation, because (to labour a point already made) if we claim that a quiddity is a dispositionality, then it will not be able to solve the problem of individuation, because that problem arose precisely because dispositionality cannot perform this role.

\section{Conclusion: back to the compound view}

As I have emphasized, my claim is not that the views in question are false, but that they are not distinct. There are good and bad consequences of this result for the participants of the debate. Clearly, neither position can claim any advantage over the other. The pure powers view cannot claim to be more parsimonious than the identity theory, but on the plus side it has access to all of the same resources that identity theorists have.

For the identity theorists, there is also good and bad news. The good news is that the incoherence objection to the identity theory fails. The bad news is that one of the reasons the identity thesis seemed so attractive was because of its supposed ability to steer between the extremes of pure powers and traditional categoricalism. Clearly if the argument of this paper is accepted, this is not so. It will specifically come as an unwelcome result that identity theory is just as susceptible to the problem of individuation as the pure powers view, since many advocates of the identity view reject the pure powers position for precisely this reason.

This does not mean that we should abandon hope of finding a middle path between traditional categoricalism and the pure powers view. Many of the issues examined in this paper are generated by the threefold identity claim at the centre of the identity thesis. However, notice that there is a position that rejects this identity claim, which still deserves to be called a powerful qualities view. This is the compound view that we encountered in Sect. 1. On this view, properties are essentially compounds of distinct dispositional and qualitative parts. Such a view is clearly distinct from the identity thesis because it does not claim an identity between the dispositional and the qualitative. This view could define the 'qualitative' in a negative way: qualitative parts of properties are those that do not contribute to the dispositions of objects that instantiate them (of course, the identity theory cannot define 'quality' in this way on pain of incoherence). ${ }^{17}$ Such a view is clearly different from the pure powers view because it claims that properties have parts that

17 Hawthorne (2001, p. 362) mentions a view like this, attributing something like it to William of Ockham (p. 377). See also Tugby (2012) for a sophisticated version of categoricalism that has some affinities with this compound view. 
are not themselves dispositional. Such a view would also be distinct from traditional categoricalism, as it would claim that a property does have dispositional parts that are essential to it.

Recall that Heil, Martin and the other powerful qualities theorists reject this view in favour of the identity thesis. However, given everything argued in this paper, the view may be due re-examination. Of course, proper elucidation of it will have to wait for further work. Specifically, it is incumbent on the compound theorist to give a characterisation of the precise relation between the two parts of the property. Such a view also faces the challenge of saying why we should accept a complex view of properties over two simpler views (pure powers and traditional categoricalism). Nonetheless, I think that the very possibility of such a view demonstrates that we should not give up on finding our middle path just yet.

Acknowledgements I would like to thank Tim Crane, Raamy Majeed and an anonymous referee for detailed comments on previous drafts of this paper. Special thanks to Matthew Tugby for many helpful and insightful comments on several previous drafts, which have improved the paper immeasurably. Thanks to Alexandria Boyle, Alexander Carruth, John Heil, Rae Langton and Hugh Mellor for discussion. Thanks also to the audience at the Moral Sciences Club in Cambridge for comments and discussion. Finally, I am very grateful to the Leverhulme Trust and the Isaac Newton Trust for an Early Career Fellowship (ECF-2015-088), which supported me while this research was carried out.

Open Access This article is distributed under the terms of the Creative Commons Attribution 4.0 International License (http://creativecommons.org/licenses/by/4.0/), which permits unrestricted use, distribution, and reproduction in any medium, provided you give appropriate credit to the original author(s) and the source, provide a link to the Creative Commons license, and indicate if changes were made.

\section{References}

Armstrong, D. (1997). A world of states of affairs. Cambridge: CUP.

Armstrong, D. (2005). Four disputes about properties. Synthese, 144, 309-320.

Barker, S. (2013). The emperor's new metaphysics of powers. Mind, 122, 605-653.

Bird, A. (2007a). The regress of pure powers. The Philosophical Quarterly, 57, 513-534.

Bird, A. (2007b). Nature's metaphysics. New York: OUP.

Bird, A. (2009). Structural properties revisited. In T. Handfield (Ed.), Dispositions and causes. New York: OUP.

Bird, A. (2012). Dispositional expressions. In G. Russell \& D. G. Fara (Eds.), Routledge companion to the philosophy of language. New York: Routledge.

Bird, A. (2016). Overpowering: How the powers ontology has overreached itself. Mind, 125, 341-383.

Carruth, A. (2016). Powerful qualities, zombies and inconceivability. The Philosophical Quarterly, 66, $25-46$.

Engelhard, K. (2010). Categories and the ontology of powers: A vindication of the identity theory of properties. In A. Marmadoro (Ed.), The metaphysics of powers: Their grounding and their manifestations. New York: Routledge.

Hawthorne, J. (2001). Causal structuralism. Philosophical Perspectives, 15, 361-378.

Heil, J. (2003). From an ontological point of view. Oxford: OUP.

Heil, J. (2005). Dispositions. Synthese, 144, 343-356.

Heil, J. (2010). Powerful qualities. In A. Marmadoro (Ed.), The metaphysics of powers: Their grounding and their manifestations. New York: Routledge.

Heil, J. (2012). The universe as we find it. Oxford: OUP. 
Heil, J. (2013). Mental causation. In E. J. Lowe, S. C. Gibb, \& R. D. Ingthorsson (Eds.), Mental causation and ontology. Oxford: OUP.

Ingthorsson, R. (2013). Properties: Qualities, powers, or both? Dialectica, 67, 55-80.

Jacobs, J. (2011). Powerful qualities, not pure powers. The Monist, 94, 81-102.

Jaworski, W. (2016). Structure and the metaphysics of mind. New York: OUP.

Lewis, D. (2001). Ramseyan humility. In D. Brandon-Mitchell \& R. Nola (Eds.), The Canberra plan. Oxford: OUP.

Locke, D. (2008). Quidditism without quiddities. Philosophical Studies, 160, 345-363.

Lowe, E. J. (2006). The four category ontology. Oxford: OUP.

Martin, C. B. (1993). Power for realists. In J. Bacon, K. Campbell, \& L. Reinhardt (Eds.), Ontology, cause and mind: Essays in homour of D. M. Armstrong. Cambridge: CUP.

Martin, C. B. (1996). Properties and dispositions. In T. Crane (Ed.), Dispositions: A debate. New York: Routledge.

Martin, C. B. (1997). On the need for properties: The road to Pythagoreanism and back. Synthese, 112, $193-231$.

Martin, C. B. (2008). The mind in nature. Oxford: OUP.

Martin, C. B., \& Heil, J. (1998). Rules and powers. Philosophical Perspectives, 12, 283-312.

Martin, C. B., \& Heil, J. (1999). The ontological turn. Midwest Studies in Philosophy, 23, 34-60.

Molnar, G. (2003). Powers. New York: OUP.

Mumford, S. (2004). Laws in nature. USA: Routledge.

Mumford, S. (2006). The ungrounded argument. Synthese, 149, 471-489.

Shoemaker, S. (1980). Causality and properties. Reprinted in D. H. Mellor \& A. Oliver (eds.) Properties. 1997/2002. New York: OUP. Citations from this version.

Smith, D. (2016). Quid quidditism est? Erkenntnis, 81, 237-257.

Strawson, G. (2008). The identity of the categorical and the dispositional. Analysis, 68, 271-282.

Taylor, J. (2013). In defence of powerful qualities. Metaphysica, 14, 93-107.

Taylor H (2017) Powerful qualities, phenomenal concepts and the new challenge tophysicalism. The Australasian Journal of Philosophy.doi:10.1080/00048402.2017.1321678

Tugby, M. (2012). Rescuing dispositionalism from the ultimate problem: Reply to barker and smart. Analysis, 72, 723-731.

Tugby, M. (2013). Platonic dispositionalism. Mind, 122, 451-480.

Vetter, B. (2013). Multi-track dispositions. The Philosophical Quarterly, 63, 330-352. 